\title{
17
}

\section{Curriculum Focused ICT - the Critical Resource}

\author{
Robert Munro \\ Department of Business and Cumputer Education, University of Strathclyde, Glasgow G13 IPP, \\ Scotland \\ r.k.munro@strath.ac.uk
}

Keywords: classroom teaching, integration of ICT, teaching materials, multimedia/hypermedia, development

\begin{abstract}
While ICT has assumed considerable importance in education its contribution to teaching and learning is frequently questioned. Educationalists focus solely on the latest technology and strongly hyped 'killer' applications, ignoring valuable software that develops skills, competences and conceptual understanding. In this paper the contribution of curriculum-oriented CDROMs to teaching and learning is exemplified through an exploration of one sophisticated resource which allows pupils to investigate differing urban environments and social history characteristics of Victorian Scotland. The paper acknowledges the many factors that inhibit the development of such CDROMs and argues that national initiatives are essential to effectively exploit the potential of this valuable educational resource.
\end{abstract}

\section{A CONFLICT OF IMPERATIVES}

The penetration and use of Information and Communications Technology (ICT) in education have been considerable since the early nineteen eighties when microcomputers were first introduced into schools. In the twenty intervening years ICT has assumed tremendous importance in the educational process. However, many educationalists have expressed concern as to whether ICT has significantly enhanced teaching and learning (Oppenheimer 1997). 
The penetration and use of ICT have been driven by a number of imperatives - not least the political imperative. This initially focused on the alleged need to create a skilled workforce and to try to create and exploit a market for computer equipment. More recently the political attention of many countries has centred on the dream of creating a knowledge society (Blair 1997). The members of this interconnected society will have ubiquitous access to ICT, be confident and competent in all aspects of its use and will exploit it to fulfil their everyday work and leisure demands. Not surprisingly, to achieve this dream, the political argument demands all school pupils gain ICT confidence and competence so they might make a smooth transition into, and an effective contribution to, the adult sector of the knowledge society.

Sadly the variations on the political imperative theme have prevailed over the key educational imperative - that of integrating ICT so that it might facilitate and support teaching and learning. Since the heady days of the nineteen eighties, many educational decision-makers have appeared more anxious to chase the technology, equip the schools with ever more advanced (yet in reality ever more rapidly obsolescent) hardware, and inculcate knowledge of how the technology and the software packages work - rather than harnessing ICT to transform the teaching and learning process.

Regrettably, they have largely neglected to consider how best this innovative, powerful and sophisticated hardware resource might be deployed and supported - by using and creating educationally relevant and significant software and courseware materials and offering appropriate programmes of teacher education - to advance pupil understanding and the development of pupil knowledge.

Over the last twenty years a welter of software innovation, much with tremendous untapped potential for transforming aspects of the educational process, has been briefly flirted with and then unceremoniously dumped as the next killer application swept in. Education is presently fixated on the Web. This is the current killer application - the salvation for education. Most administrators, parents, teachers and pupils exhibit an obsessive desire to see this ICT resource incorporated into every facet of education in every classroom.

The hype behind the selling of the Web has resulted in its public acceptance as the catalyst of the knowledge revolution - the engine of the knowledge society - the Holy Grail for ICT where all the data, information and, indeed, answers and solutions to any issue resides. Many in education sincerely believe that all learners, no matter the context, can and will turn to the Web for data on any issue or topic, transform the data they instantly unearth into information and spin these threads of information into cloths of 
rich knowledge. Unfortunately this idealised scenario reflects the increasing expectation held by all sectors of society.

The Web is a fantastic resource. It is the ultimate multimedia/hypermedia delivery system for education. Ironically, it is an educational resource that most teachers are still struggling to effectively exploit. They find it difficult to handle, difficult to search, difficult to locate data which matches their demands and very difficult to usefully incorporate into their teaching strategies and their pupils' learning. Their pupils, often more technologically adept, would rather use the Web for social interaction in chat rooms than slake their thirst for knowledge with a search engine.

The Web may well prove to be the Holy Grail of education but current over-reliance on it, and an unquestioning commitment to it, really does teaching and learning a disservice. I am convinced that the multimedia/hypermedia delivery system is the most effective and valuable use of ICT in education. However, until the Web is more available and accessible, is easier to search and also to integrate into classroom activity, I contend that CD-ROM delivery of educational resources is more valuable to teachers and learners.

The aforementioned difficulties associated with the Web, the sheer size and range of data which is available and the bewildering choice and complexity of multifarious search engines and directories are instantly obviated by presenting material on CD-ROM. The teacher is presented with a focused resource where all content is easily accessible and all the extraneous noise of the Web is stripped away.

Given the current plethora of CD-ROMs on the education market it may appear strange to argue for even more development. However, the resources I envisage that would be of most benefit are not the comprehensive encyclopaedias like Encarta and Grolier or many of the topic-oriented products that are frequently written at a high academic level and contain but a small volume of content applicable to the curriculum. Teachers need CDROMs with a particular and precise curriculum focus. These should encapsulate the entire gamut of media resources woven together and specially structured to assist the teacher to help all pupils in their class to find relevant data, identify significant information, use software tools to manipulate the data and arrive at meaningful conclusions on trends, relationships and results. Varied interaction with the resource should enhance understanding of concepts, issues, events and actions. 


\section{THE STRATHCLYDE CONTRIBUTION}

While such a resource can be successfully deployed across the curriculum it has proved of particular benefit in Art, Geography, History and Modern Studies. Initiatives at the University of Strathclyde have resulted in the production of curriculum-oriented CD-ROMs for all these areas.

Some are aimed at the teacher training student e.g. The Language of Art (Ewing 1997) which was designed to foster the understanding of, and the classroom use of, specific art techniques. Most, however, have been developed to address a particular curriculum topic and have been specifically targeted at pupils aged between 10 and 16 (in Scotland this represents the last two years of Primary school education and the first four years of Secondary education). These resources are all underpinned by the desire to enhance children's understanding of a specific curriculum area and to offer opportunities to explore and research this area.

Looking at Art, Coutts and Hart (1998) and Scanning the City (Coutts et al. 1999) attempt to stimulate discussion of Art and Design issues and encourage pupils to experiment with particular art techniques. Scotland's Weather (Munro 1998) runs under a Web browser and offers students a comprehensive resource on weather data and conditions for an entire year, including dynamic spreadsheets and a stunning set of almost 400 European satellite photographs. There is a growing suite of resources in History which comprises Moving House, Glasgow: A Tale of Two Cities, Tiree: Famine and Clearance 1840-1900, Doon The Watter, and Auld Reekie and the Dear Green Place (Hillis and Calderhead 1993-2001).

While all of these products encompass a common aim their design and development has been quite different - reflecting the different teaching styles adopted in these subject/curricular areas. A brief examination of the structure and content of one such package will illustrate the important contribution they can make to enhancing teaching and learning.

The quaintly named Auld Reekie and the Dear Green Place gives little indication of the content - unless you are Scottish! This history resource deals with life in the two major Scottish cities of Edinburgh (Auld Reekie or the old smoky town) and Glasgow (The Dear Green Place - so called because of the remarkably large areas given over to parkland and gardens) during Victorian times - 1850-1900. This is the most recent in a series of electronic courseware resources which have addressed historical concepts associated with change over time, differing societal groupings, varied conditions of urban life, disparities in and between different areas of similar urban environments and general lifestyle problems experienced by people in the past. 
In order to provide pupils with a comprehensive picture of life in Victorian times, to enable them to compare and contrast situations both within and between the two major urban centres of Scotland, and to help them to assess past scenarios with life of the present, the advantages afforded by multimedia/hypermedia to make available an eclectic set of resources were used to their fullest. Teachers would have found it incredibly difficult to gain access to many of the rich and diverse resources that were gathered together for this CD-ROM - let alone collect these resources together and present them to their pupils for exploration and analysis. It has always been a paradox that, while History has such a vast media resource base, teachers frequently find their knowledge of it to be incomplete, their access to it inhibited and their ability to acquire much of severely constrained (often financially).

On this CD-ROM all facets of different mediums are represented:

- Historical maps of different areas of the two cities

- Detailed maps/plans of Sandyford Place and the Gorbals areas of Glasgow and Royal Terrace and the Cowgate areas of Edinburgh

- Population Census data for the years 1851 and 1891 for these four areas held in a database of over 2000 records

- Textual detail of many of the families who lived in the affluent areas of Sandyford Place and Royal Terrace

- Pictures/photographs of many of the heads of these families manufacturers, industrialists and professionals - who often held important social positions

- Archive photographs and film illustrating environmental conditions and issues

- Local press cuttings and newspaper advertisements from the nineteenth century

- Old plans of houses

- Textual extracts/transcripts from books and articles - notably on the bodysnatchers 'Burke and Hare', suitably embellished with sound effects!

- Interviews - text, audio and video

- Modern day photographs and video film of the areas and of house interiors

- Songs and music of Victorian times - plus theatre bills/programmes

- Sketches and drawings.

This rich set of resources was selected to provide pupils with a full and detailed picture of contrasts in urban life during Victorian times. It was then organised into selected groupings or topics - illustrated in Figure 1. 


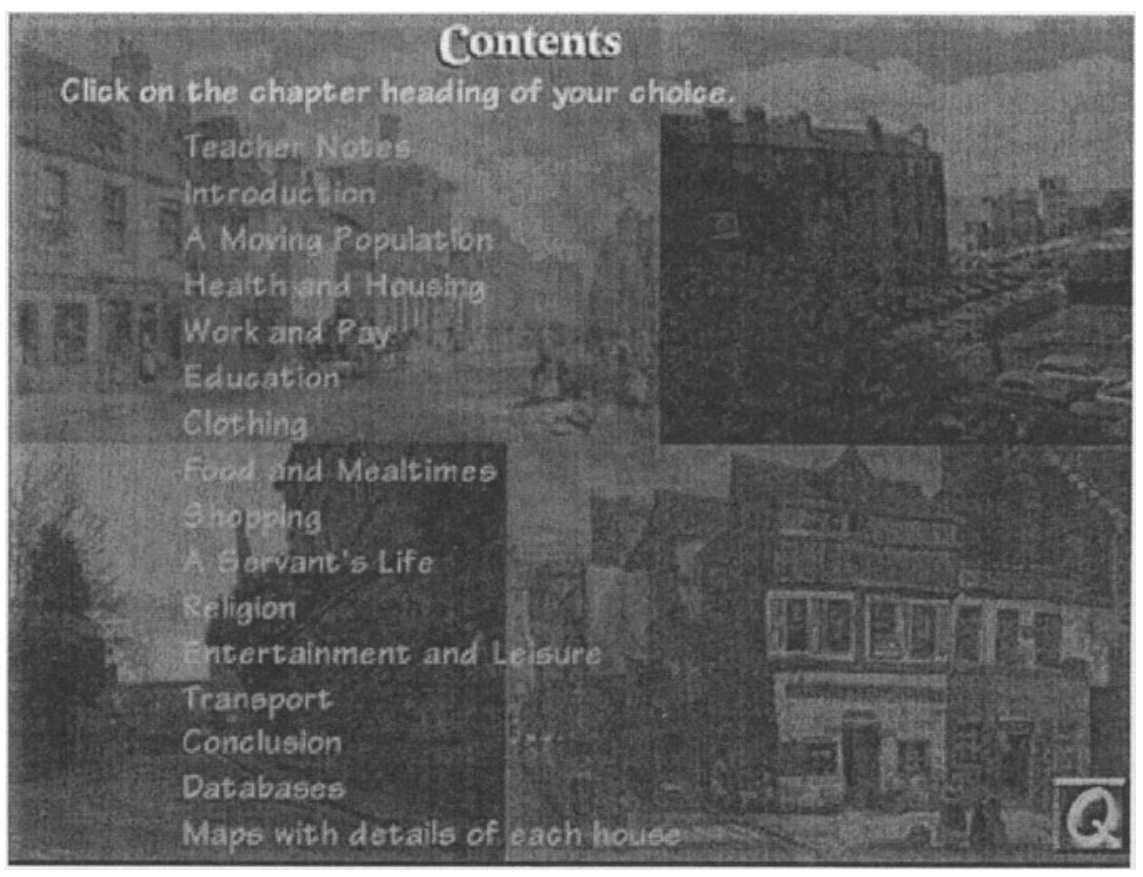

Figure 1. Auld Reekie and the Dear Green Place - main topics

These were carefully chosen to afford pupils the scope, within the general thrust of exploring contrasting lifestyles, to investigate independently or collaboratively a particular issue or area of interest. They can examine a particular urban area over a period of time or they could compare and contrast one area with another. They are encouraged to share their findings and conclusions on any issue or topic they investigate, with other groups. It is therefore possible to build up class profiles of certain areas, social classes or particular socio-economic and environmental issues.

To help pupils investigate or research in a purposeful way and to focus their attention on specific topics and important elements of these topics, a range of tasks were incorporated into the CD-ROM framework. These tasks lead the pupils to many key conclusions and help them grasp major historical concepts - secure foundations for further development. The tasks provide effective scaffolding and are differentiated to ensure the different abilities of learners are accommodated. The inclusion of structured tasks reflects a genuine attempt to help pupils learn, and indeed learn how to learn. These tasks are not prescriptive - the Teachers Notes clearly state that 'Each chapter contains suggested pupil tasks which should be supplemented depending on the use of the program'. 


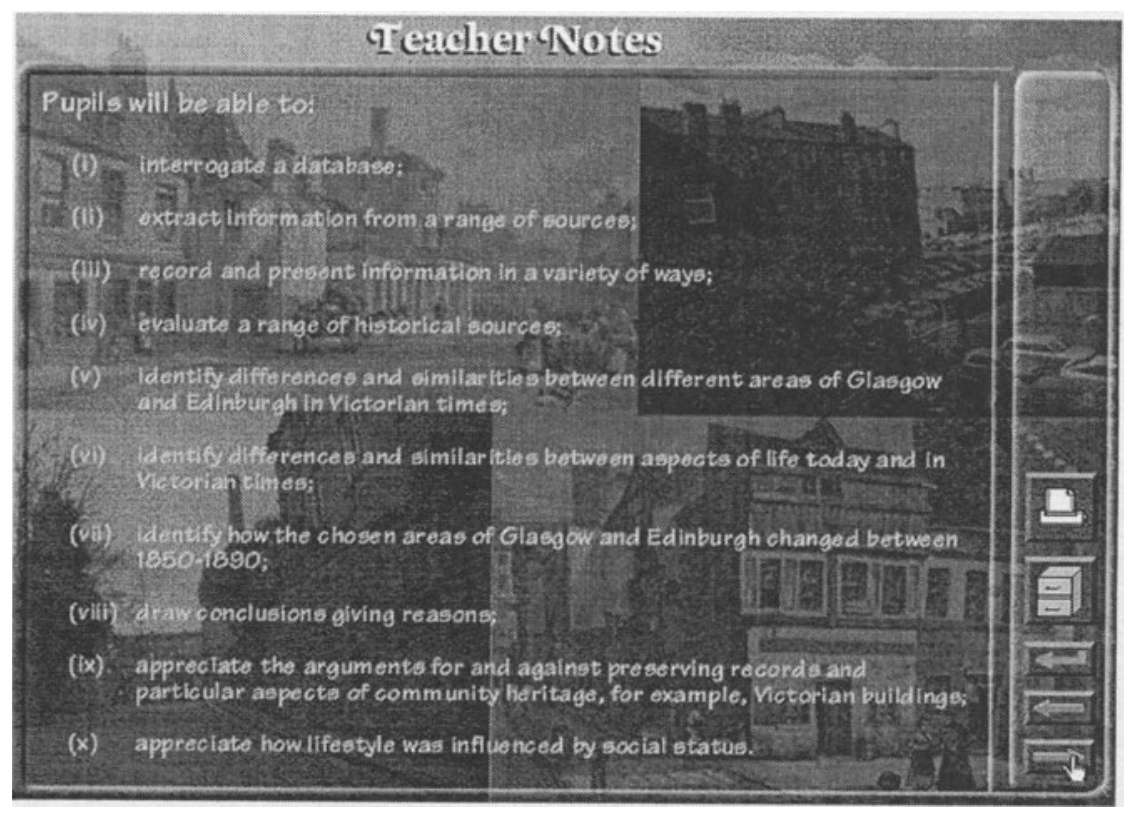

Figure 2. General skills developed using Auld Reekie and the Dear Green Place

The Teacher Notes (Figure 2) are extremely important. The development of the CD-ROM took into account the problems that teachers had reported in using ICT in the classroom and the difficulties they had experienced in teaching aspects of this topic in the past. This coloured the selection of resources and the topics selected for investigation. It also influenced the writing of the tasks and investigative activities for the pupils.

In Scotland primary school teachers and secondary school teachers of History have to teach within the parameters of the document Environmental Studies 5-14 (SOED 1993) which lays down skills pupils must acquire and levels of competence they should attain. Teachers are reassured to find that both the general 5-14 skills which may be achieved through activities associated with this CD-ROM (see Figure 2), as well as the detailed skills which should result from coverage of specific topics, are clearly listed.

Aware of the problems which pupils experience when interrogating databases, a simple user-friendly (and to date foolproof) search facility was created. For pupils who experience difficulties in reading text, audio commentaries were provided on longer text passages and a mouse click displays a pop-up definition of difficult words or phrases. The user can 'blow-up' pictures, plans, maps and advertisements and then scrolls the enlarged image. This technique allows the user to scroll detailed street maps, 
click on properties and access pictures of individual houses and associated census detail (Figure 3). For example, if 10 Royal Terrace is accessed, the user can discover that, in 1851, this property was owned by David Marshall, a retired sea captain who had worked for the East India Company. He lived with his wife, two sons, daughter and three servants. In 1891 his widow Christina, aged 75, was still living in the house with one of the sons but had five servants to attend to their needs.

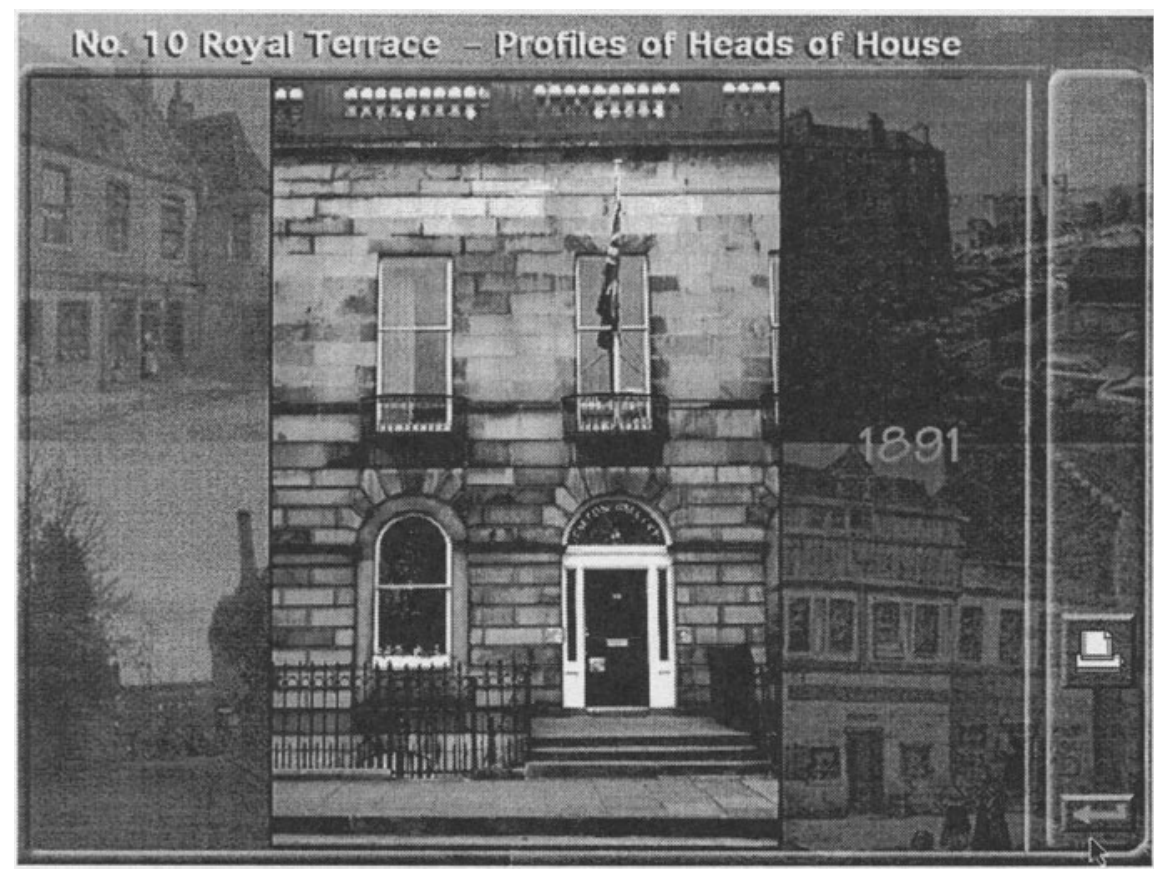

Figure 3. A rather splendid property - 10 Royal Terrace, Edinburgh

The program enhancements were implemented to reduce the frustrations which are often experienced by users of ICT in classrooms - both teachers and pupils - and to ensure the learning process is enhanced, not inhibited, by technology! All the resources were knitted together using MacroMind Director and the resultant CD-ROM is a seamless, comprehensive resource which teachers can deploy in myriad ways in classrooms - with every pupil! They can do so confident that all the learning is related to a specific area of the curriculum or syllabus. There are detailed teaching notes and suggestions for use for any teacher unsure as to how this resource might be integrated into their teaching strategy.

Through independent and collaborative investigation of these resources pupils will develop greater awareness of events and the social fabric of the 
past. They will be able to explain and account for problems and issues and reflect on how life today varied from or resembled life in the past

\section{THE RESOURCING DILEMMA}

The beauty of this form of ICT is that it eases access to and integration of the many different and diverse resources and media formats which together can afford a vivid illustration of, and spark an explanation of, the past. One small disc can bring to classrooms a set of resources that would be impossible to provide in their primary or raw form. This richness and versatility is not deliverable in any other acceptable format.

Unfortunately few examples of this type of valuable curriculum resource have been created for teachers to use in schools. Most CD-ROM resources are of the encyclopaedic variety - valuable but daunting in their content and frequently lacking a curricular focus. Those targeted at specific curriculum areas are desirable but are expensive to produce and often are not commercially viable. CD-ROM resources are also expensive in terms of development time - time to identify and collect together resources, to examine and organise resources into a usable framework, to create learning tasks which realise the teaching potential of the resources and to mount the composite resource electronically in a structured, integrated, accessible and user-friendly multimedia format. This last task demands the input of skilled educators married with the input of skilled courseware developers who have developed particular expertise with specialist authoring software.

Consequently, few national educational organisations are prepared to underwrite the development of curriculum-oriented resources on CD-ROM. Many teachers are therefore turning to the Web for help. There are curriculum specific resources here, often courtesy of educators in the USA, which, because of different curricular foci and teaching strategies/formats have to be significantly modified for classroom use. Similar modification is usually necessary for topic-oriented Web resources created by commercial organisations or charities. Few teachers can afford the time to trawl for resources which require extensive modification or identify what appear to be potential resources but turn out to be yet another listing of resources. Bad experiences just result in opportunities to foster ICT integration being wasted.

We have had twenty years of politically led and directed ICT development. Surely it is time to reappraise the role of ICT in education and focus our activity on the enhancement of the teaching and learning process. This can only be sustained if the software/courseware resource base is widened, users are freed from the many constraints and difficulties currently 
posed by ICT and teachers are supported through the provision of curriculum relevant resources and pedagogical training. The establishment of national initiatives designed to create a pool of curriculum-oriented electronic multimedia/hypermedia resources which teachers can access and obtain for use in their classrooms would represent a major contribution to the realignment of ICT in education. These resources could be progressively mounted on the Web so that they could be deployed as, and when, the Web becomes an ubiquitous educational resource.

\section{REFERENCES}

Blair, A. (1997) Connecting the Learning Society. HMSO, London.

Coutts, G. and Hart, D. (1997) Looking at Art. CD-ROM, University of Strathclyde, Glasgow.

Coutts, G. et al. (1999) Scanning the City. CD-ROM, University of Strathclyde, Glasgow.

Ewing, S. (1997) The Language of Art. CD-ROM, University of Strathclyde, Glasgow.

Hillis, P. and Calderhead, D. (1993) Moving House. CD-ROM, University of Strathclyde, Glasgow.

Hillis, P. and Calderhead, D. (1994) Glasgow: A Tale of Two Cities. CD-ROM, University of Strathclyde, Glasgow.

Hillis, P. and Calderhead, D. (1996) Tiree: Famine and Clearance 1840-1900. CD-ROM, University of Strathclyde, Glasgow.

Hillis, P. and Calderhead, D. (1998) Doon The Watter. CD-ROM, University of Strathclyde, Glasgow.

Hillis, P. and Calderhead, D. (2001) Auld Reekie and the Dear Green Place. CD-ROM, University of Strathclyde, Glasgow.

Munro, R. (1997) Scotland's Weather. CD-ROM, SCET/Scottish Office, Edinburgh.

Oppenheimer, T. (1997) The Computer Delusion. The Atlantic Monthly, Vol. 280, No. 1, pp. 45-62.

SOED (Scottish Office Education Department) (1993) Environmental Studies 5-14.

Edinburgh.

\section{BIOGRAPHY}

Robert Munro is a senior lecturer in the Department of Business and Computer Education who has been involved in developing the ICT skills of teachers for over fifteen years. He has directed numerous ICT research projects and helped create a range of educational software, particularly for History and Geography teaching. 